\title{
Have you done time, doc?
}

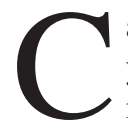

an you trust a criminal to tell you the truth? If that criminal is applying to practice as a physician, Canadian medical regulatory authorities say that, for the most part, you can.

Though hospitals and medical schools in Canada are increasingly requiring criminal record checks on new employees and students, provincial medical licensing bodies - even those that require the checks for entry to practice - remain skeptical that such mandatory screening is necessary.

They argue the number of doctors who lie about their criminal history is negligible, although they do not publish statistics on such practitioners. They also claim dishonest doctors couldn't hide a criminal history for long, even in the absence of criminal records screening. But others argue mandatory screening of doctors is inevitable and a prerequisite of demonstrating that the profession does an adequate job of self-regulation.

Requiring criminal records checks at entry to practice is more a matter of maintaining public confidence in the vetting process for physicians than it is a measure in response to real threats to patient safety, says Dr. Ed Schollenberg, registrar for the College of Physicians and Surgeons of New Brunswick. "We started doing them on everyone three years ago. ... If we didn't have this process, I'm not aware we would have missed anything significant. But then again, if you make a policy not to do something that other people are doing you have to be able to live with the consequences."

It's also a preventive step for selfregulators, he adds. "If a problem develops later you don't want to be explaining why you didn't do x or y."

The College of Physicians and Surgeons of British Columbia was the first regulatory authority in Canada to instate comprehensive criminal records screening of doctors when it mandated background checks as a requirement for entry to practice in 1995 . Subsequent amendments now obligate the College

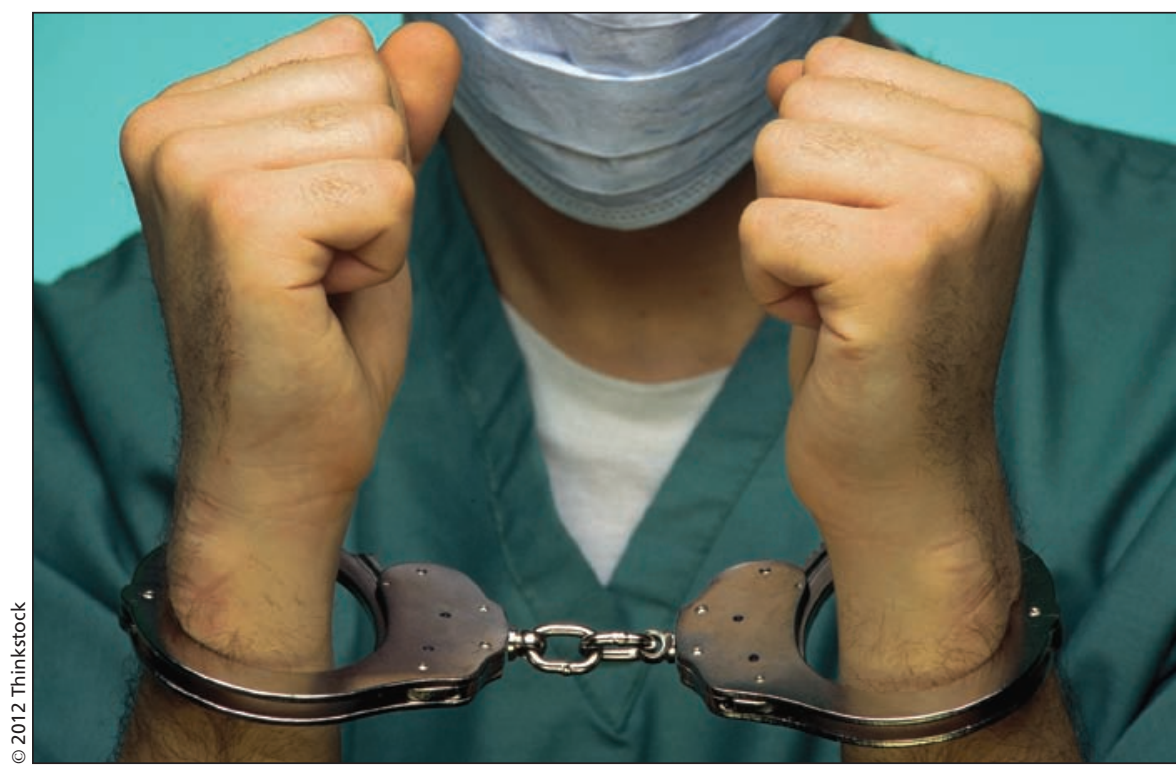

Four provinces - Manitoba, Ontario, Quebec and Nova Scotia - require criminal record checks at point of entry to practice.

to rescreen members every five years.

"Essentially, the review is a statutory requirement that this College is obligated to enforce. It obviously has nothing to do with [physician] trustworthiness. It is the law," Susan Prins, director of communications for the College, writes in an email.

Medical regulatory authorities in Manitoba, Ontario, Quebec and Nova Scotia have since introduced similar screening at point of entry to practice, largely as a consequence of security concerns arising from increased physician mobility, says Dr. Yves Robert, president of the Federation of Medical Regulatory Authorities of Canada.

In some provinces, the introduction of screening coincided with demands for background checks from hospitals.

At the time, physicians expressed concern "about where that information would go," Schollenberg says. "By definition every hospital here is relatively small, with a couple hundred physicians, and some did express concern if information was passed onto a medical staff office in a hospital that it could get shared through a comment in an elevator or something like that."
Most Canadian medical schools require background checks for students, even in provinces in which medical licensing bodies do not, such as Saskatchewan.

For the College of Physicians and Surgeons of Saskatchewan, "it's a question of cost [versus] benefit," says Bryan Salte, associate registrar and legal counsel. "What you're doing is putting 1600 or 1900 physicians through a significant amount of administrative burden. And is the benefit at the end of that worth what you'll actually gain?"

"If the answer is you're going to find a significant number of child molesters then absolutely it would be the case," he adds. "Our college didn't see the significant benefit likely to be achieved as a result of putting in the requirement."'

College of Physicians and Surgeons of Alberta Registrar Dr. Trevor Theman concurs. Blanket criminal record screening would be "bureaucratically a big hassle" for a relatively small return, he says. "In 14 years, I don't know of a single example of someone found to have a record that was significant."

Schollenberg counters that New Brunswick's experience indicates that 
screening isn't an enormous hassle. It's "relatively painless" and the administrative costs are simply added to physician application fees, he says.

A "very minor percentage" of physicians fail to disclose their criminal records and subsequently are flagged during screening, he adds. "Off the top of my head I can recall four. ... We do 300 full locum applications a year ... so you're dealing with a fraction of $1 \%$."

Most of the hits are for "the usual DUIs [driving under the influence] and perhaps some drug issues in their misspent youth" which generally don't prevent regulators from granting a license. But failing to disclose recent charges and convictions does raise questions about an applicant's character, Schollenberg adds.

Those numbers are surely "really low," Robert says. But there are "unfortunately no statistics because of the inconsistency from one province to the other. It's not really useful to maintain statistics that will give a number of persons that is less than the number of fingers on your two hands."

Theman and Salte say they're unaware of any physicians having lied on an application in Alberta or Saskatchewan, let alone lied about a criminal record. Such a devious character wouldn't escape regulatory scrutiny for long, they say.

"Saskatchewan is a pretty small place and everybody knows everything about everybody. If there is a serious criminal offense and a physician is named somebody will know about it," Salte says. Moreover, "no physician is ever allowed to move from province to province until the regulatory body in the province they're moving from signs a certificate indicating here's our knowledge of this person and they have or haven't been disciplined."

International medical graduates aren't a concern because they're subject to immigration checks, "so the likelihood of someone with criminal past coming in is quite low," he adds.

Schollenberg typically garners more information about an incoming physician from Google than he does from a criminal records check. "I've had letters from people in federal prisons, people who just got out from federal prison and one fellow who got charged in Florida for impersonating a physician, and those were just [cases] where something about the story looked suspicious. And so with Google and a few other sources you can find out enough to tell you this is someone you don't want to deal with."

But such an informal and intuitive method of obtaining information about an applicant is perhaps only of value to a smaller province, Schollenberg adds. "New Brunswick is a lovely place but people from California tend not to decide to come here out of the blue."
Reports of disciplinary action are shared between provinces but information about applicants who were denied licensure or withdrew their applications is inconsistently shared between jurisdictions.

"Part of it is avoiding an overabundance of information," Schollenberg says. "We sometimes get emails from one of the neighbouring provinces saying we've just found out this guy's documents are questionable or something like that. But it's kind of ad hoc."

Robert, though, believes nationwide adoption of mandatory criminal record checks at entry to practice would ensure that no one slips through the seams.

It's not only a matter of due diligence, but ultimately one of "the confidence of the public" in the profession's ability to self-regulate, he adds. "Probably it's a matter of time. Everyone will standardize their process." - Lauren Vogel, CMAJ

\section{CMAJ 2012. DOI:10.1503/cmaj.109-4113}

First of a three-part series:

Part 2: A check a day keeps the bad apple away (www.cmaj.ca/lookup /doi /10.1503/cmaj.109-4114).

Part 3: Are you kidding, doc?

(www.cmaj.ca/lookup/doi/10.1503

/cmaj.109-4115).

\section{A check a day keeps the bad apple away}

\section{$\mathrm{M}$} andatory criminal records screening for physicians may be little more than a bow to an unnecessary formality in the eyes of Canadian regulators, but practitioner licensing bodies elsewhere in the world contend such screening is crucial to weeding out bad apples.

Canadian medical regulatory authorities, including ones that perform background checks as a condition of entry to practice, argue that such screening is largely superfluous. They assert that the number of doctors who lie about previous criminal charges or convictions is negligible and could easily be found out through less systematic methods such as self-disclosure (www.cmaj.ca /lookup/doi/10.1503/cmaj.109-4113).

But similar regulatory bodies in the United States, Australia and England assert that background checks identify shady characters who would otherwise slip through the vetting cracks and have proven an invaluable tool in obtaining more rapid treatment for doctors who might, for example, be inclined to seek solutions from a bottle.

"There are not a lot of physicians who have been convicted of a felony. But they do exist and it's incumbent upon us when we license somebody to ensure that they meet the minimum qualifications," says Kathleen Selzler Lippert, executive direc- tor of the Kansas State Board of Healing Arts - one of 45 state medical licensing boards in the US that conduct background checks at entry to practice. "We expect people to be honest and this provides an independent verification."

Some medical regulatory authorities who have introduced background checks as a matter of course were surprised to discover just how many applicants either forgot or lied about their criminal past.

The North Carolina Medical Board wasn't aware it had a "fairly significant problem" until mandatory screening for new applicants was introduced in 2003, says Jean Fisher Brinkley, director of public affairs for the board. Now, there's 